\title{
Accelerated Atherosclerosis in Systemic Lupus Erythematosus: Role of Proinflammatory Cytokines and Therapeutic Approaches
}

\author{
Chary López-Pedrera, ${ }^{1}$ Maria Ángeles Aguirre, ${ }^{1}$ Nuria Barbarroja, ${ }^{2}$ \\ and Maria José Cuadrado ${ }^{3}$ \\ ${ }^{1}$ Unidad de Investigación, Hospital Universitario Reina Sofia, Instituto de Investigacion Biomédica de Córdoba (IMIBIC), \\ E-14004 Córdoba, Spain \\ ${ }^{2}$ Hospital Virgen de la Victoria, Fundación IMABIS, E-29010 Málaga, Spain \\ ${ }^{3}$ Lupus Research Unit, St Thomas Hospital, London SE1 7EH, UK
}

Correspondence should be addressed to Chary López-Pedrera, rosario.lopez.exts@juntadeandalucia.es

Received 15 January 2010; Revised 21 June 2010; Accepted 26 July 2010

Academic Editor: Timothy B. Niewold

Copyright (C) 2010 Chary López-Pedrera et al. This is an open access article distributed under the Creative Commons Attribution License, which permits unrestricted use, distribution, and reproduction in any medium, provided the original work is properly cited.

\begin{abstract}
Systemic lupus erythematosus (SLE), a chronic multisystem autoimmune disease with a broad range of clinical manifestations, is associated with accelerated atherosclerosis (AT) and increased risk of cardiovascular complications. Relevant factors directly influencing the development of AT comprise immune complex generation, complement activation, and changes in the production and activity of a complex network of cytokines, including type I and II interferons, B lymphocyte stimulator (BLyS), TNF $\alpha$, IL6, IL-17 and migration macrophage inhibitor (MIF). Autoantibodies, also responsible for cytokine expression and activation, play a supplementary key role in the development of AT. Genomic and proteomic studies have contributed to the discovery of genes and proteins involved in AT, including some that may be suitable to be used as biomarkers. All that data has allowed the development of new drugs, most of them evaluated in clinical trials: inhibitors of IFN and TNF $\alpha$, B cell directed therapies, synthetic oligodeoxynucleotides, intravenous immunoglobulin, or statins. The focus of the present paper is to summarize recent evidence showing the role of cytokines in the development of AT in SLE and the rationale, and safety concerns, in the use of combined therapy to prevent AT and cardiovascular disease.
\end{abstract}

\section{Introduction}

SLE is a chronic multisystem autoimmune disease with a broad range of clinical manifestations, including photosensitive skin rashes, discoid lesions, arthritis/arthralgia, nephritis, cardiac and pulmonary disease, and CNS disorders. The disease pathogenesis is attributed to circulating antinuclear autoantibodies against a variety of nuclear antigens (including dsDNA, the ribonucleoprotein (RNP) complex Ro, the RNA-binding protein LA, RNPs, the RNA molecule/protein complex Sm, the C1 complement component subunit C1q, and phospholipids) and the dysfunction of $\mathrm{T}$ and $\mathrm{B}$ lymphocytes and dendritic cells [1].

Although the pathogenesis is believed to lie in the dysregulation of the immune system, the involvement of various organ systems often leads to secondary morbidities resulting from renal failure, hypertension, or CNS disorders, and more recently it is becoming increasingly clear that accelerated atherosclerosis associated with SLE may contribute to premature mortality [2].

Atherosclerosis (AT) is a chronic inflammatory disease of the arteries associated with various risk factors that promote lipid abnormalities (i.e., dyslipidemia), development and progression of atherosclerotic lesions, plaque rupture, and vascular thrombosis [3]. AT is enhanced in autoimmune diseases; noninvasive investigations show increases in intima-media thickness, carotid plaque, and coronary artery calcifications in patients with antiphospholipid syndrome (APS), systemic lupus erythematosus (SLE), and rheumatoid arthritis (RA) compared to controls [4]. The reason for this accelerated process is still debatable and, although traditional risk factors (such as hyperlipidemia, smoking, obesity, hypertension, diabetes mellitus, postmenopausal status, and sedentary lifestyle) are more prevalent in those 


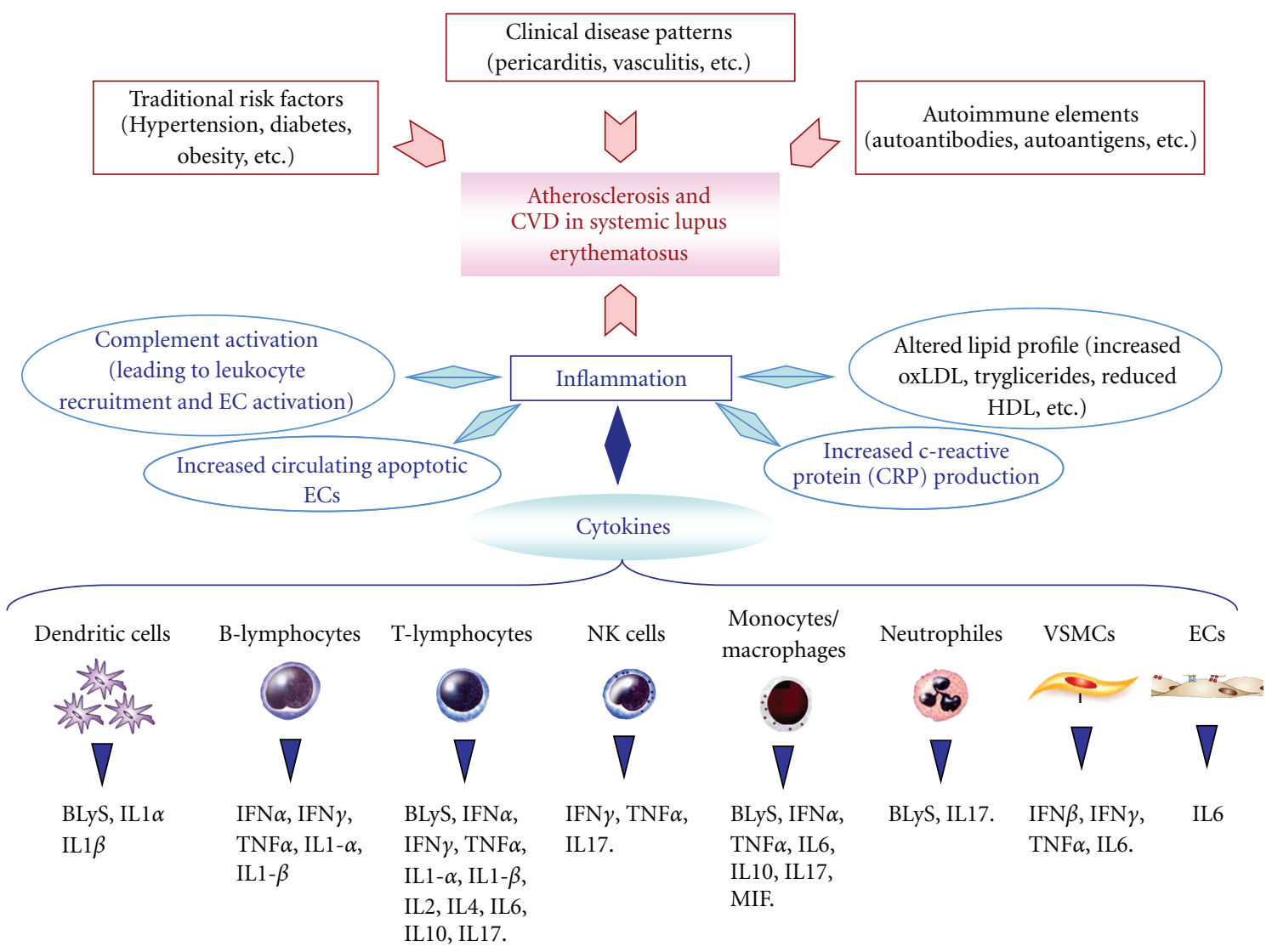

FIGURE 1: Mechanisms leading to atherogenesis and Cardiovascular disease in SLE patients. ECs: endothelial cells; VSMCs: vascular smooth muscle cells; TNF: tumour necrosis factor; ILs: interleukins; IFN: interferon; BLyS: B lymphocyte stimulator.

patients than in general population, they do not seem to fully explain that enhanced risk [5].

Experimental studies and human observations suggest that innate and adaptive immune responses participate in the pathogenesis of both AT and autoimmune diseases. Actually, some autoantibodies, including antioxidized low density lipoproteins (antioxLDL), anti $\beta$-2-Glycoprotein 1 (antiß2GPI), antiHeat shock proteins 60/65 (antiHSP60/65), and antioxLDL/ $\beta 2 \mathrm{GPI}$, have been shown to be associated to the pathogenesis of AT $[6,7]$. However, their role in accelerated AT in APS and SLE patients is still controversial.

Identified additional factors for AT in patients with SLE include chronic inflammation and chronic exposure to steroid therapy. These factors can directly influence the development of AT through a variety of mechanisms such as immune complex generation, complement activation, alteration of the oxidant-antioxidant balance locally within the vessel wall, and changes in the production and activity of a complex network of cytokines [8-10] (Figure 1).

Characterization of the molecular and cellular basis of signalling abnormalities within the immune system that lead to auto reactivity and inflammation and their relationship to early atherosclerosis and cardiovascular disease (CVD) development remain critical for understanding the pathogenesis of SLE.

\section{Cytokines as Immune Mediators Involved in Atherosclerosis and CVD Development}

The vascular inflammatory response involves complex interaction between inflammatory cells (neutrophils, lymphocytes, monocytes, and macrophages), endothelial cells (ECs), vascular smooth muscle cells (VSMCs), and extracellular matrix (ECM). Vascular injury is associated with increased expression of adhesion molecules by ECs and recruitment of inflammatory cells, growth factors, and cytokines, with consequent effects on ECs, VSMCs, and ECM. Cytokines include tumour necrosis factor, interleukins, lymphokines, monokines, interferons, colony stimulating factors, and transforming growth factors. Cytokines are produced by macrophages, T-cells and monocytes, as well as platelets, ECs and VSMCs [11]. Depending on their cellular source, cytokines are classified into type 1 cytokines, produced by Th1 T-helper cells, that include IL-2, IL-12, IFN- $\gamma$, and TNF- $\beta$; and type 2 cytokines, produced by Th2 T-helper cells that include IL-4, $-5,-6,-10$, and -13 . Th1 cytokines tend to drive cellular inflammatory responses including macrophage activation. The Th2 cytokines play a role in distinct inflammatory processes, and may inhibit certain forms of autoimmunity [12]. Circulating cytokines interact with specific receptors on various cell types and activate 
signalling pathways leading to an inflammatory response involving cell adhesion, permeability, and apoptosis [11].

Cytokines are master regulators of the innate and adaptive immune response and, unsurprisingly, are known to regulate and, essentially, coordinate many stages of atherosclerosis $[13,14]$. Many cytokines, such as Interleukin (IL)-1, IL-6, IL-10, interferon IFN $\gamma$, and TNF $\alpha$ are expressed highly in atherosclerotic regions and exhibit pro- and antiatherogenic actions [13-15].

Innate cytokines such as IL-1 or TNF may activate endothelial cells (ECs), vascular smooth muscle cells (VSMCs), monocytes/macrophages, lymphocytes ( $\mathrm{T}, \mathrm{B}$, $\mathrm{NK}$ ), dendritic cells, and mast cells. These vascular cells can actively contribute to the inflammatory cytokine-dependent response in the vessel wall by production of cytokines or eliciting responses to cytokines, or can be involved in cytokine-mediated interaction with invading cells such as monocytes, T-cells, or mast cells. Activation of these pathways results in accumulation of cells and increased LDL- and ECM-deposition which may facilitate subsequent invasions [11].

Numerous abnormalities of the cytokine network have been described in patients with SLE as well as in murine lupus models. Some of them were shown to play a pivotal physiopathological role in certain T-cell, B-cell or antigen presenting cell dysfunctions characteristic of the disease, while others are more likely to be innocent bystanders [16].

\section{Cytokines Involved in the Pathogenesis of Atherosclerosis in SLE}

Several cytokines with relevance to CVD has been proven to be related to the pathogenesis of AT in SLE. In the following paragraphs we highlight some of the most likely significantly involved.

Plasmacytoid dendritic cells (pDC) activated by immune complexes containing nucleic acids secrete type I IFN (IFN $\alpha$ and IFN $\beta$ ) in SLE. Type I IFN causes differentiation of monocytes to myeloid-derived dendritic cell $(\mathrm{mDC})$ and activation of autoreactive $\mathrm{T}$ and $\mathrm{B}$ cells. Patients with SLE have an increased expression of type I IFN-regulated genes because of a continuous production of IFN $\alpha$. Recent reports have demonstrated that elevated levels of type I IFNs (cytokines with potent antiproliferative and antiangiogenic effects, and associated with active SLE disease, and positivity for some autoantibodies) could lead to endothelial dysfunction through the promotion of a reduction in the number of endothelial progenitor cells (EPCs, responsible for the neovascularization in sites of endothelial injury), thus contributing to the increased CV risk observed in SLE [17]. In that way, a recent study by Denny and coworkers [18] showed that SLE patients displayed not only significant decreases in the number of circulating EPCs, but also significant impairments in the capacity of EPCs/CACscirculating angiogenic cells to differentiate into mature ECs and synthesize adequate levels of proangiogenic molecules vascular endothelial growth factor (VEGF) and hepatic growth factor (HGF). Moreover, that study showed that lupus EPCs/CACs had increased IFN $\alpha$ expression. By contributing to endothelial disjunction/damage and inducing proinflammatory responses within the atherosclerotic plaque, IFNs could promote AT in patients with SLE.

The role of the type II interferon (IFN $\gamma$ )-whose expression is significantly increased in peripheral blood mononuclear cells (PBMCs) of SLE patients [19] —in the progression of atherosclerosis has been well debated due to evidence conveying both pro- and antiatherogenic actions of the cytokine. Since IFN $\gamma$, known to be a proinflammatory cytokine, can also display antiinflammatory properties [20], it is likely that it acts in both ways in AT. These conflicting actions may well be gene-specific and it is known that approximately a quarter of all genes within the transcriptome of the macrophage, a key immune cell involved in AT, is sensitive to IFN $\gamma$ [21]. IFN $\gamma$ has been shown to influence many features of atherosclerosis such as foam cell formation, the adaptive Th1-specific immune response and plaque development [22]. In the global context of AT, it is possible that its proatherogenic actions out-weight its antiatherogenic ones. Nevertheless, the precise role of this type of IFN in the development of AT in SLE patients remains to be analyzed.

IFNs are often profoundly dysregulated in SLE, and both IFN $\alpha$ and IFN $\gamma$ have been shown to induce B lymphocyte stimulator (BLyS) expression. BLyS (also known as the B cell-activating factor belonging to the TNF family, or BAFF [23]) was identified as a novel TNF family ligand, and has proven to be a key factor in the selection and survival of B cells [23-26]. The BLyS protein is expressed by a wide variety of cell types, including monocytes, activated neutrophils, $\mathrm{T}$ cells and DCs [27-29]. Although standing levels of BLyS are constitutively generated, its expression and secretion can be potentiated by inflammatory cytokines, such as IL-2, TNF $\alpha$, and IFN $\gamma$ [28-31]. BLyS levels affect survival signals and selective apoptosis of autoantibody-producing B cells. High levels of BLyS may relax B cell selection and contribute to autoantibody production, exacerbating the SLE disease state. It has been hypothesised a potential cooperative action of BLyS and IFNs in the aetiology of SLE. Since BLyS is not known to have direct or immediate proinflammatory activities, changes in serum BLyS levels are unlikely to trigger acute inflammatory reactions and disease manifestations. However, it is possible than an increase in disease activity may lag behind increases in circulating BLyS levels due to indirect or "delayed" effects of BLyS in the systemic immuneinflammatory reactions of SLE. Nevertheless, the possible association between the overexpression of BLyS and the development and/or progression or AT or CVD in SLE patients remains elusive.

$\mathrm{TNF} \alpha$ is both a proinflammatory and an immunoregulatory cytokine. TNF $\alpha$ has differential effects on monocytes, on B cells, on T cells, and on dendritic cells, as well as on the process of programmed cell death. TNF $\alpha$ is a growth factor for B lymphocytes, and B lymphocytes are able to produce significant amounts of TNF $\alpha$ in an autocrine loop [32]. TNF $\alpha$ may also exert a significant influence on B cells by its capacity to induce IL-6 [33]. Moreover, TNF $\alpha$ stimulation leads to increased production of IFN $\gamma$, a cytokine with a clear-cut pathological role in SLE, as previously described 
[34]. TNF $\alpha$ also constitutes an activating cytokine and a maturation factor of dendritic cells, which are essential in immune regulation and have also been implicated in autoimmunity in general, and in SLE in particular [35]. In addition, the elevated circulating levels of TNF $\alpha$ found in SLE patients have been found to be associated with high triglyceride and low HDL levels [36]. Moreover, in a recent study by Rho and coworkers [37] it was established a significant association between TNF $\alpha$ expression levels and the severity of coronary calcium scores in SLE patients. Yet, that data should be further confirmed in a new cohort of patients, as a previous study by Roman et al. [38] found no association among TNF $\alpha$, IL6, or CD40L and the presence of carotid plaque in SLE.

Nevertheless, because of its wide involvement in the activity of monocytes, dendritic cells, and lymphocytes as well as in the expression of other inflammatory cytokines involved in AT development, TNF $\alpha$ may be considered a major factor in SLE-related CVD, acting both by contributing to hypertriglyceridaemia and by promoting atherosclerosis-related inflammation.

Interleukin-6 (IL-6) is a pleiotropic cytokine with a wide range of biological activities that plays an important role in immune regulation and inflammation. Furthermore an association between IL-6 and lupus was demonstrated in murine models of SLE and blocking IL-6 improved lupus in all models tested [39]. IL-6 is one of the most important $\mathrm{B}$ cell stimulating factors that induces the differentiation of $\mathrm{T}$ cells into effectors cells. Immunoglobulin and antiDNA antibody production in vitro by B cells from lupus patients has been demonstrated to be promoted by IL- 6 and inhibited by antibodies against IL-6 or the IL-6 receptor. IL-6 is involved in the recruitment of inflammatory cells and lipid homeostasis and is associated with increased cardiovascular mortality and prognosis in the general population. Moreover, IL-6 drives c-reactive protein (CRP) production, which itself plays multiple roles, influencing key promoters of AT; moreover, it appears as an independent predictor of coronary events [40]. However, the role of IL-6 in the pathogenesis of SLE-related AT is also controversial. Some authors found elevated IL-6 levels only in cases with increased CRP, concluding that it is part of the acute phase response [41]. Others defend the idea that the relationship between IL- 6 concentrations and the burden of AT in SLE patients represents more than an epiphenomenon, and that measurement of IL- 6 provides supplementary information in this cohort of SLE patients [42].

IL-17 is a pro-inflammatory cytokine which participates in the defence against certain pathogens, primarily extracellular bacteria and fungi [43]. IL-17 is produced by several cell subsets including CD4+ T cells, CD8 + T cells, NK cells and neutrophils [43]. In addition to its proinflammatory capacity, IL-17 exerts its effects through the recruitment of monocytes and neutrophils by increasing the local production of chemokines (IL-8, monocyte chemoattractant protein-1, growth-related oncogene protein-alpha) [4448], the facilitation of $\mathrm{T}$ cell infiltration and activation by stimulating the expression of intercellular adhesion molecule-1 [49] as well as the amplification of the immune response by inducing the production of IL-6, prostaglandin E2, granulocyte-macrophage colony-stimulating factor and granulocyte colony-stimulating factor $[50,51]$. Additionally, IL-17 synergizes with other cytokines, in particular with IL-1 $\beta, \mathrm{TNF} \alpha$, and IFN $\gamma$ [52-55]. Th17 cells have been implicated in the pathogenesis of autoimmune diseases including rheumatoid arthritis [56] and multiple sclerosis [57], and recent evidence suggested that IL-17-mediated inflammation might play a role in the pathogenesis of SLE. Also abnormally high levels of IL-17 and IL-23 have been reported in human SLE sera [58], and more recently it has been provided evidence that IL-17 production by $\mathrm{T}$ cells is increased in SLE patients [59]. That study further described that double negative (C4-CD8-) T cells, which are expanded in the peripheral blood of patients with SLE [60], represent major producers of IL-17, and that they undergo a vigorous proliferative response following stimulation.

A very recent study [61] has demonstrated a concomitant presence of IL-17 and IFN $\gamma$ in patients and clinical specimens of coronary atherosclerosis, the presence of IL-17/IFN $\gamma$ dualproducing $\mathrm{T}$ cells within coronary plaques, and a synergistic effect of IL-17 and IFN $\gamma$ on elicitation of proinflammatory cytokine and chemokine production by cultured human VSMC. Thus an association of this cytokine with human coronary AT has been already established. However, its role in SLE-related AT remains to be evaluated.

Macrophage migration inhibitory factor (MIF) has emerged as a potential link between SLE and atherosclerosis development [10, 62]. Increased serum levels of MIF have been detected in SLE patients compared with healthy control individual. MIF is a pleiotropic cytokine with roles in several inflammatory diseases. MIF induces the pro-inflammatory mediators TNF $\alpha$, IL-1, IL-6 and MMPs. It can activate T cells, promote angiogenesis and induce proliferation of cells, while inhibiting p53 expression and apoptosis of the same cells $[62,63]$. MIF can be induced by oxLDL, which is an initiating factor in atherogenesis, and so expression of MIF early on may enhance pro-inflammatory responses and lesion progression [63].

The interaction between CD40 and CD40L is also an integral part of the inflammatory pathway in the vascular system. CD40 ligation on cells of the vascular wall promotes mononuclear cells recruitment and contributes to thrombosis in the setting of atherosclerosis [64]. The co-stimulatory molecule CD40 ligand (CD40L, also called sCD154) is a member of the TNF family and participates in B cell differentiation and proliferation [65] as well as in antibody isotype switching [66]. The binding of CD40L to its receptor, CD40, is thought to also be involved in atherogenesis and atherosclerotic plaque rupture [67-69]. Some reports indicated elevated serum concentrations of CD40L in patients with SLE compared to matched control subjects [70, 71]. CD40L has been found to be over expressed in T cells of patients with SLE [72], and elevated concentrations of CD40 and CD40L have been found in atherosclerotic plaques in SLE patients [67].

An important outcome derived from the studies reported on this area is that only for a few cytokines there is sufficient consistent data allowing classifying them as typically 
proatherogenic (IL6, IL17,IFN $\gamma$, TNF $\alpha$, BAFF, MIF, etc) or antiatherogenic (IL-10), and that some cytokines (IFN $\gamma$, TNF $\alpha$, IL4, IL-6) can exert pro- or antiatherogenic effects depending on the disease status. This knowledge can be used for improved early detection, prevention and treatment of atherosclerosis in SLE.

\section{Genomics and Proteomics Biomarkers for SLE Atherosclerosis and Cytokine Involvement}

Several genomic studies have been developed on SLE PBMCs [73-79] (Table 1). Genomic studies have consistently given strong support to the involvement of a dysregulation of IFNdependent pathways in the pathogenesis of SLE $[80,81]$. Analysis of SLE-upregulated genes showed a predominance of genes known to be upregulated in response to IFN. In some cases, expression results obtained using DNA microarrays were also confirmed by independent methods such as quantitative real-time reverse transcription PCR $[79,82]$. Additional changes that may be of great importance in determining the high thrombotic risk of SLE patients include the upregulation of other gene families such as TNF and TNF receptor, chemokines and chemokine receptors, cell surface activation antigens, FC receptors, metalloproteinases, and defensins [80]. Interestingly, many of the expression changes observed in PBMCs isolated from SLE patients were reproduced in healthy PBMCs cultured with IFN $\alpha$ [76]. The lack of detection of significant IFN $\alpha$ transcripts in SLE patient's PBMCs supported that this cytokine may be mainly produced by plasmacytoid dendritic cells located in the patient's tissues [76].

Recent searches for "lupus genes" through candidate single nucleotide polymorphism (SNP) association scans, have further demonstrated that SLE is a disease with complex genetic inheritance and no single causative gene [86]. These studies have also given more proofs of the relationship between genetic profiles and development of AT and CVD in SLE patients. Among them, polymorphisms in the region of the TNFAIP3 gene were recently linked to SLE [83]. TNFAIP3 encodes the deubiquitinating enzyme A20, and endogenous inhibitor of the nuclear factor-kappaB $(\mathrm{NF} \kappa \mathrm{B})$ pathway. $\mathrm{NF} \kappa \mathrm{B}$ is a transcription factor that is activated by TNF or IL-1/TLR signalling pathways, which induces transcription of proinflammatory genes. In $\mathrm{AT}, \mathrm{NF} \kappa \mathrm{B}$ is activated at sites of the arterial wall that are prone to lesion development. SNPs in the TNFAIP3 gene region may cause reduced expression or reduced activity of A20 [83], therefore contributing to an uncontrolled inflammatory response and autoimmunity and potentially accelerated AT in these patients.

The proteomic analysis of plasma samples from SLE patients has allowed an important observation in order to understand the higher susceptibility of SLE patients to suffer CV disorders. Pavón et al. [87] have studied by 2-DE plasma samples from SLE patients and healthy controls of initially unknown haptoglobin ( $\mathrm{Hp}$ ) phenotype, and tryptic digests of the excised Hpa polypeptide chain spots were analyzed by MALDI-TOF/MS. Selected tryptic peptides were then sequenced by nano-(n)ESI-IT MS/MS. There were remarkable interindividual differences in the Hp patterns of SLE patients compared with those of healthy controls. Thus, Hpa1F protein was only present in one of the patients studied, whereas the Hpa2 isoform was detected in all but one SLE patients studied, resulting in an $\mathrm{Hp} 2$ allele frequency significantly higher than that in healthy controls. Hp functions as an antioxidant and an essential endothelial protector by binding to free haemoglobin, avoiding oxidative stress [88]. Both the hemoglobin-binding and the antioxidant capacity of Hpal is higher compared with that of Hpa2 [89] and Hp genotype plays a critical role in the oxidative and inflammatory response to intraplaque haemorrhage [90]. Moreover, Hp genotype modulates the balance of inflammatory (Th1) and antiinflammatory (Th2) cytokines produced by macrophages exposed to free haemoglobin, which may have implications in understanding interindividual differences in the inflammatory response to haemorrhage [91]. Moreover, large-artery elasticity index and small-artery elasticity index were significantly lower and systemic vascular resistance was higher in homozygotes for the 2 allele ( $\mathrm{Hp} \mathrm{2-2)}$ compared with patients with Hp 2-1 or Hp 1-1 phenotypes [92]. The knowledge of the Hp phenotypes and their PMF by 2-DE and MS in SLE patients can help predicting or preventing $\mathrm{CV}$ disorders and determining a more precise prognosis and better treatment [87].

There are still scarce data in that area, and studies performed are very heterogeneous. However, fundamental pathobiological mechanisms in atherogenesis development, and their association to autoimmune-mediated induction of cytokine expression have been identified in SLE. Nevertheless, genomic and proteomic areas are in continuous development and new information on genetic factors and gene and protein expression patterns in a near future are warranted.

\section{SLE Treatment and Its Influence on Cytokine Expression and Atherosclerosis Development}

The pharmacological management of SLE is challenging, owing to its unpredictable clinical course, the variable organ system involvement and the lack of clear understanding of disease pathogenesis.

Traditional management of SLE has included the use of nonsteroidal antiinflammatory drugs, antimalarials, glucocorticoids, and immunosuppressive drugs such as azathioprine, methotrexate, cyclosporine A, cyclophosphamide, and mycophenolate mofetil [93-95]. Although many of these therapies have shown great efficacy, they are often associated with adverse effects. The development of safer therapies for SLE has led to recent emphasis on targeting selected pathways that can be important in the inflammatory response in SLE. In this context, a better understanding of lupus pathogenesis has led to the development of biological agents that are directed at biomarkers including, inhibitors of cytokines (e.g., TNF $\alpha$ or IL-10), B-cell directed therapies, statins, and so forth. 
TABLE 1: Genomic markers of CVD risk and atherosclerosis in SLE. Some examples of genes from each category are given.

\begin{tabular}{|c|c|c|c|c|c|}
\hline \multicolumn{3}{|c|}{ Genes/proteins associated with CVD and atherosclerosis } & \multirow[t]{2}{*}{$\begin{array}{c}\text { Technique } \\
\text { utilized }\end{array}$} & \multirow[t]{2}{*}{ Change } & \multirow[t]{2}{*}{ References } \\
\hline Gene & Protein & Accession & & & \\
\hline \multicolumn{6}{|c|}{ Genes differentially expressed in PBMCs from SLE patients } \\
\hline \multicolumn{6}{|c|}{ IFN target genes } \\
\hline IFIT1 & $\begin{array}{l}\text { Interferon-induced protein with } \\
\text { tetratricopeptide repeats- } 1\end{array}$ & X06559 & & $\mathrm{Up}$ & \\
\hline G1P3 & Interferon, alpha-inducible protein (IFI-6-16) & U22970 & & $\mathrm{Up}$ & \\
\hline IFIT4 & $\begin{array}{l}\text { Interferon-induced protein with } \\
\text { tetratricopeptide repeats } 4\end{array}$ & O14879 & & Up & \\
\hline PLSCR1 & Phospholipid scramblase 1 & $\mathrm{O} 15162$ & & Up & \\
\hline G1P2 & Interferon, alpha-inducible protein (IFI-15K) & M21786 & & $\mathrm{Up}$ & \\
\hline IRF7 & Interferon regulatory factor 7 & Q92985 & & $\mathrm{Up}$ & \\
\hline THBS1 & Thrombospondin 1 & $\mathrm{~J} 04835$ & & Up & \\
\hline FCGR1A & Fc fragment of IgG, high-affinity Ia receptor & M63830 & & Up & \\
\hline USP20 & Ubiquitin specific protease 20 & Y17457 & & Down & \\
\hline MATK & Megakaryocyte-specific tyrosine kinase & S75164 & & Down & \\
\hline \multicolumn{6}{|c|}{ TNF and TNF receptor families } \\
\hline TNFSF10 & TNF-related apoptosis inducing ligand (TRAIL) & $\mathrm{U} 37518$ & $\begin{array}{l}\text { DNA } \\
\text { microarrays }\end{array}$ & $\mathrm{Up}$ & {$[73-80]$} \\
\hline TNFRSF10C & TRAIL receptor 3 & O14798 & & Up & \\
\hline FAS & Fas (TNF receptor superfamily, member 6) & D31968 & & Up & \\
\hline \multicolumn{6}{|c|}{ Chemokines and chemokine receptors } \\
\hline CCR7 & Chemokine (C-C motif) receptor 7 & L31584 & & Up & \\
\hline $\operatorname{ILSRB}$ & Interleukin 8 receptor, beta & M99412 & & Up & \\
\hline \multicolumn{6}{|c|}{ Cell surface activation antigens } \\
\hline CD69 & CD69 molecule & Z30426 & & $\mathrm{Up}$ & \\
\hline \multicolumn{6}{|l|}{ Fc receptors } \\
\hline FCGR1A & Fc-gamma receptor I A1 & M63830 & & Up & \\
\hline FCGR2A & $\begin{array}{l}\text { Fc fragment of IgG, low affinity IIa, receptor } \\
\text { (CD32) }\end{array}$ & A21604 & & Up & \\
\hline \multicolumn{6}{|c|}{ Metalloproteinases } \\
\hline MMP3 & Matrix metallopeptidase 3 & J04732 & & $\mathrm{Up}$ & \\
\hline MMP9 & Matrix metallopeptidase 9 & D10051 & & Up & \\
\hline \multicolumn{6}{|l|}{ Defensins } \\
\hline DEFA3 & Defensin 3, neutrophil-specific & L12691 & & Up & \\
\hline \multicolumn{6}{|c|}{ Single nucleotide polymorphism (SNP) association scans } \\
\hline Gene & Protein & SNPs & Effect & & References \\
\hline TNFAIP3 & De-ubiquitinating enzyme A20 & $\begin{array}{c}\text { rs13192841 } \\
\text { rs2230926 } \\
\text { rs6922466 }\end{array}$ & $\begin{array}{l}\text { Reduced } \\
\text { expression } \\
\text { and activity } \\
\text { of A20 }\end{array}$ & & {$[83]$} \\
\hline IRF5 & IFN-regulatory factor 5 & rs2004640 & $\begin{array}{l}\text { Increased risk } \\
\quad \text { for SLE }\end{array}$ & & {$[84]$} \\
\hline STAT4 & Transcription factor & rs7574865 & $\begin{array}{l}\text { Increased risk } \\
\text { for SLE }\end{array}$ & & {$[85]$} \\
\hline
\end{tabular}


In SLE, the loss of self-tolerance leads to persistence and activation of auto reactive $\mathrm{B}$ cells and T cells with the consecutive abnormal secretion of cytokines and production of autoantibodies, which are thus interesting target candidates for the development of novel SLE therapies. Several cytokines have been identified as major targets in SLE, leading to the development of numerous monoclonal antibodies, some of them currently used in therapy or under clinical evaluation [96].

A therapeutic option in patients with SLE is inhibition of IFN $\alpha$. Three general approaches could be used to target IFN $\alpha$ : (1) reduce extra-cellular levels of IFN $\alpha$; (2) reduce signalling from the IFN $\alpha$ receptor; (3) reduce the activity of the mediators of IFN $\alpha$ activity. Each approach has been shown to display pros and cons and implications for efficacy and safety needs to be weighed. Nevertheless, recent data from a phase I clinical trial suggests that administration of neutralizing monoclonal antibodies against IFN $\alpha$ can ameliorate disease activity [97].

The foregoing evidence clearly implicates TNF in the accelerated atherogenesis and other cardiovascular events associated with autoimmune diseases such as rheumatoid arthritis (RA) and SLE. Several TNF antagonists are currently licensed for the treatment of RA, including infliximab, adalimumab (a fully humanized monoclonal antibody) and etanercept (a fusion protein of human soluble TNF receptor and the Fc component of human IgG). All of these biologic agents have been shown to be effective in controlling disease activity, as well as reducing systemic inflammation [98-100], surrogate vascular and metabolic markers [101, 102], and CVD events [103].

Limited studies have evaluated the effect of antiTNF therapy in SLE, and are discussed in a recent revision by Karim et al. [104]. The study by Aringer et al. [105] looked at six patients with active SLE treated with infliximab plus azathioprine or methotrexate. Disease activity declined during therapy despite the fact that levels of anti-dsDNA antibodies and cardiolipin increased in four out of six patients. Four out of six patients who had lupus nephritis improved their proteinuria significantly. There were associated infections including urinary tract infection in three patients, one of whom also had Escherichia coli septicaemia, and a prolonged suspected viral fever in another patient. In the followup study Aringer et al. [106] also showed an increase in antibody detection to DNA, histone, chromatin and $\operatorname{IgM}$ cardiolipin, despite an overall reduction in disease activity. TNF $\alpha$ antagonist therapy has also been associated with a lupus-like syndrome; most of these case reports occurred in patients receiving either etanercept or infliximab [107].

A small open trial used antilL-10 monoclonal antibodies in six patients with active SLE [108]. Ten patients received intravenous IL-10 monoclonal antibody $20 \mathrm{mg}$ for 21 days and were followed for 6 months. The SLEDAI score decreased significantly by day 21 , and was maintained at 6 months. Skin and joint symptoms improved in all patients. Prednisolone dose reduced significantly over the 6-month period.

Another approach was recently developed, based on active immunotherapy, which consists of inducing antibodies able to neutralize the interaction of the self-cytokine to its receptor. In that way, in a model of RA, it was demonstrated that vaccination with a biologically inactive but immunogenic human TNF $\alpha$ derivative (keyhole limped hemocyaninhuman TNF $\alpha$ heterocomplex), led to the production of high titters of antibodies that neutralize human $\mathrm{TNF} \alpha$ bioactivity [109].

Other novel cytokines that might have a role, as implicated by vascular epidemiologic and pathophysiologic studies, could also be tested in the near future in the SLE context, including IL17 or IL23, which are being investigated in clinical trials for managing of RA. Despite the positive results found in these studies with anticytokine therapies, numerous side effects have also been demonstrated. As cytokine network dysregulation is highly complex in SLE, further investigations are needed to evaluate whether this strategy may be advantageous in SLE in the future.

$B$-cell directed therapies are promising treatments for SLE patients that do not respond to the first-line therapies. Rituximab is a chimeric antiCD20 monoclonal antibody which depletes B cells from the peripheral circulation, but allows regeneration from stem cells. CD20 is expressed at various stages of B-cell development from pre-B cells up to mature B cells, but not on plasma cells and hematopoietic stem cells. The exact mechanisms of action in autoimmune disease is however as yet unknown. Rituximab causes lysis of $\mathrm{B}$ cells mediated by complement and by Fc-receptor-bearing cytotoxic cells, and also causes apoptosis. It has a variable effect on immunoglobulin levels with variable reduction of autoantibody titres. It is possible that rituximab has additional effects on the immune system [110-112]. Several groups have published uncontrolled studies of rituximab treatment in SLE with positive results [113-119]. Adverse events most frequently were infections and a risk of relapse significantly elevated.

A very recent study has investigated the changes in the lipid profile of SLE patients after B-cell depletion therapy [120]. They reported that rituximab acted positively on known risk factors for premature AT such as HDL cholesterol, the total cholesterol/HDL ratio and Tissue Factor (TF) levels. This improvement in the lipid abnormalities coincided with decreased disease activity as measured by the BILAG index and a fall in the antidsDNA antibody levels. Since rituximab has not known direct effects on lipid metabolism, it seems likely that the positive effects in the lipid profile of that set of patients is indirectly mediated through a reduction in the inflammatory activity of the disease. Larger prospective studies should evaluate if this favourable effect contributes to a lower incidence of $\mathrm{CV}$ events.

Several studies have demonstrated increased levels of hypomethylated CpG-containing DNA in sera from patients with SLE, which may contribute to the initiation and/or perpetuation of the disease. Thus, recent therapies have been focused on the use of synthetic oligodeoxynucleotides $(O D N)$ capable of "neutralizing" or "inhibiting" immune responses by inhibiting the activity elicited by this altered DNA. Among them, phosphorothioate ODN mimic the immunosuppressive activity of the repetitive TTAGGG motifs present in mammalian telomeres. These TTAGGG 
multimers block the production of pro-inflammatory and $\mathrm{T}$ helper type 1 cytokines elicited when immune cells are activated by a wide variety of Toll-like receptor ligands (TLRs), polyclonal activators, and antigens. The suppressive activity of such ODN has been attributed to their interference with the phosphorylation of signal transducer and activator of transcription 1 (STAT1) and STAT4, thereby blocking the inflammation mediated by STAT-associated signalling cascades. These findings suggest that TTAGGG multimers may find broad use in the treatment of diseases characterized by over-exuberant/persistent immune activation. [121].

Intravenous immunoglobulin (IVIgs) therapy has been also used for the treatment of SLE. Various mechanisms of IVIgs have been shown to play a role in the modulation of SLE: IVIgs suppresses the expansion of autoreactive B lymphocytes through signalling the Fc $\gamma$ RIIB, idiotypemediated inhibition of $B$ cell receptors and neutralisation of cytokines such as the B cell survival factors (B cell activation factor- $B$ cell activating factor belonging to the TNF family (BLyS) and A proliferation-inducing ligand (APRIL)-) [122]. In case reports and in open trials, high-dose IVIgs $(2 \mathrm{~g} / \mathrm{Kg}$ over a 5-day period) has consistently been shown to be a beneficial and safe adjunct therapeutic agent for over 20 manifestations in patients with SLE [123]. The use of IVIgs seems to be particularly successful in those patients with active disease and concomitant sepsis [MJ Cuadrado, personal communication].

Statins may also play an important role in the treatment of SLE patients regarding the prevention of cardiovascular disease as well as the immunomodulation over the chronic inflammatory activity of the disease. The pleiotropic properties of statins, in addition to their effects on the suppression of cholesterol synthesis, include direct influence on endothelium, plaque formation and thromboxan synthesis as well as direct and indirect immunomodulatory activities.

Statins have further demonstrated their antithrombotic/ antiinflamatory effects on APS patients. In a preliminary study, our group evaluated the effects of Fluvastatin treatment on monocyte expression and regulation of the main proteins involved in the characteristic procoagulant/proinflammatory state of APS patients [124]. Twenty patients with APS and previous history of thrombosis received Fluvastatin $(20 \mathrm{mg} /$ day $)$ for one month. After one month of Fluvastatin treatment, monocytes from APS patients showed a significant inhibition of TF, proteaseactivated receptors (PAR)-1 and PAR-2, VEGF and Flt1 expression. Proteomic analysis showed significant changes in the protein patterns of monocytes from APS after Fluvastatin administration, particularly on proteins involved in thrombotic development: inhibiting Annexin II and RhoA expression and increasing that of Protein Disulphide Isomerase. The data of this study supported that Fluvastatin have multiple profound effects in monocyte activity, which are directly related to thrombosis prevention in APS patients.

A recent study by Ferreira et al. [125] demonstrated a surprisingly reduction of SLE activity measured by SLEDAI scale after atorvastatin therapy in addition to the improvement of the endothelial-dependent vasodilatation in SLE patients after a 8 weeks controlled trial. In support for this observation, Kotyla et al. [126] observed similar reduction of SLEDAI in the group of female patients treated with another statin: simvastatin. Reduction of SLEDAI was accompanied by a prominent suppression of TNF $\alpha$ concentration in sera of patients treated. That phenomenon was observed just after 4 weeks of treatment with simvastatin at a dose of $20 \mathrm{mg}$. They also reported improvement of endothelial function, leading to the thesis that restoration of endothelial function was not restricted to the single compound (atorvastatin) but may be recognized as a class of drug effect. Since TNF $\alpha$ is believed to mediate endothelial damage, that authors also speculated that suppression of TNF $\alpha$ levels after statin therapy might be one mechanism via which restoration of endothelial function occurs.

Because contradictory results were obtained in NZB/W mice that were given atorvastatin, either orally or intraperitoneally [84], and no significant effects of fluvastatin on cardiac events in renal transplant recipients with SLE has been observed in a very recent study [127], the preliminary positive findings must be confirmed by multicentre and long-term studies to define whether statin treatment in SLE patients is indeed associated with a relevant reduction of cardiovascular morbidity and mortality as well as with an amelioration of the inflammatory status and if this drug category should be broadly indicated for SLE patients.

In sum, cytokines identified as major players in the path physiology of SLE, which have been selected as targets for the development of novel therapies (including IFNs, TNF or Th1 cytokines), have also proved to influence the development of AT and CVD in that autoimmune disease. Therefore, therapies directed to reduce or eliminate their expression would give a double benefit for SLE patients: the control of the disease, and the prevention of AT and CVD development.

\section{Conclusions}

In spite of the significant and continuous advances performed in the discovery of the cellular and molecular mechanisms responsible for SLE-related AT, relevant questions remain still unanswered: what are the direct links between chronic inflammation and the initiation and progression of vascular stiffening and AT? What are the safest and most effective pharmacologic approaches to limit inflammation even in the absence of disease-related activity?

Cytokine upregulation constitute a major mechanism that links increased atheroma formation in patients with SLE. However, because of the cytokines' function overlap, their redundant activity, and their synergistic or antagonistic activity, (which may depend on the cell type, the local environment, the presence of synergistic or competing factors, and tissue responsiveness to each cytokine), their pathophysiological role may be difficult to assess.

A plethora of new treatment approaches using antibodies or small molecule inhibitors specifically targeting cytokines, cellular receptors, or signalling mechanisms has emerged in recent years. All of them have shown limited effectiveness, and, in a similar way to what happened with the "traditional treatments" administered to SLE patients, showed a number of adverse effects. Nevertheless, the knowledge continues 
increasing, and there are two lessons to learn from the experience to date: (1) that no single treatment is effective and safe enough; and (2) that every single patient shows a cellular and molecular profile that physicians should seriously take into consideration.

Anti-inflammatory therapeutic strategies in the setting of SLE-related AT need to consider a network of interactive cytokines rather than individual proinflammatory factors in isolation. Genetic profiles may also be relevant to the severity of the disease and the response to each specific drug. Probably the best therapeutic strategy would imply a combination of immunosuppressant and antiinflammatory drugs, which should further be administered taking into account the cellular and molecular profile specific of each SLE patient.

\section{Acknowledgments}

Ch. L. Pedrera was supported by a contract from the Fundación Progreso y Salud of the Junta de Andalucía government of Spain. This work was supported by grants from the, "Junta de Andalucía" (exp 0042/2007, 0246/2009, and P08-CVI-04234) and the Health Ministery (exp PS09/01809) of Spain.

\section{References}

[1] D. P. D’Cruz, M. A. Khamashta, and G. R. Hughes, "Systemic lupus erythematosus," The Lancet, vol. 369, no. 9561, pp. 587-596, 2007.

[2] M. Petri, "Detection of coronary artery disease and the role of traditional risk factors in the Hopkins Lupus Cohort," Lupus, vol. 9, no. 3, pp. 170-175, 2000.

[3] N. Bassi, A. Ghirardello, L. Iaccarino et al., "OxLDL/ $\beta 2$ GPIanti-oxLDL/ $\beta 2$ GPI complex and atherosclerosis in SLE patients," Autoimmunity Reviews, vol. 7, no. 1, pp. 52-58, 2007.

[4] Y. Shoenfeld, R. Gerli, A. Doria et al., "Accelerated atherosclerosis in autoimmune rheumatic diseases," Circulation, vol. 112, no. 21, pp. 3337-3347, 2005.

[5] E. Matsuura, K. Kobayashi, and L. R. Lopez, "Preventing autoimmune and infection triggered atherosclerosis for an enduring healthful lifestyle," Autoimmunity Reviews, vol. 7, no. 3, pp. 214-222, 2008.

[6] Q. Xu, G. Schett, H. Perschinka et al., "Serum soluble heat shock protein 60 is elevated in subjects with atherosclerosis in a general population," Circulation, vol. 102, no. 1, pp. 14$20,2000$.

[7] K. Kobayashi, M. Kishi, T. Atsumi et al., "Circulating oxidized LDL forms complexes with $\beta$ 2-glycoprotein I: implication as an atherogenic autoantigen," Journal of Lipid Research, vol. 44, no. 4, pp. 716-726, 2003.

[8] I. Avalos, Y. H. Rho, C. P. Chung, and C. M. Stein, "Atherosclerosis in rheumatoid arthritis and systemic lupus erythematosus," Clinical and Experimental Rheumatology, vol. 26, supplement 51, pp. S5-S13, 2008.

[9] S. I. van Leuven, J. J. P. Kastelein, D. P. D’Cruz, G. R. Hughes, and E. S. Stroes, "Atherogenesis in rheumatology," Lupus, vol. 15, no. 3, pp. 117-121, 2006.

[10] L. E. Full, C. Ruisanchez, and C. Monaco, "The inextricable link between atherosclerosis and prototypical inflammatory diseases rheumatoid arthritis and systemic lupus erythematosus," Arthritis Research \& Therapy, vol. 11, no. 2, pp. 217-226, 2009.

[11] A. H. Sprague and R. A. Khalil, "Inflammatory cytokines in vascular dysfunction and vascular disease," Biochemical Pharmacology, vol. 78, no. 6, pp. 539-552, 2009.

[12] S. Gordon, "Alternative activation of macrophages," Nature Reviews Immunology, vol. 3, no. 1, pp. 23-35, 2003.

[13] A. Tedgui and Z. Mallat, "Cytokines in atherosclerosis: pathogenic and regulatory pathways," Physiological Reviews, vol. 86, no. 2, pp. 515-581, 2006.

[14] V. C. Mehra, V. S. Ramgolam, and J. R. Bender, "Cytokines and cardiovascular disease," Journal of Leukocyte Biology, vol. 78, no. 4, pp. 805-818, 2005.

[15] J. L. Young, P. Libby, and U. Schönbeck, "Cytokines in the pathogenesis of atherosclerosis," Thrombosis and Haemostasis, vol. 88, no. 4, pp. 554-567, 2002.

[16] B. R. Lauwerys and F. A. Houssiau, "Involvement of cytokines in the pathogenesis of systemic lupus erythematosus," Advances in Experimental Medicine and Biology, vol. 520, pp. 237-245, 2003.

[17] P. Y. Lee, Y. Li, H. B. Richards et al., “Type I interferon as a novel risk factor for endothelial progenitor cell depletion and endothelial dysfunction in systemic lupus erythematosus," Arthritis and Rheumatism, vol. 56, no. 11, pp. 3759-3769, 2007.

[18] M. F. Denny, S. Thacker, H. Mehta et al., "Interferon$\alpha$ promotes abnormal vasculogenesis in lupus: a potential pathway for premature atherosclerosis," Blood, vol. 110, no. 8, pp. 2907-2915, 2007.

[19] A. Csiszár, GY. Nagy, P. Gergely, T. Pozsonyi, and É. Pócsik, "Increased interferon-gamma (IFN- $\gamma$ ), IL-10 and decreased IL-4 mRNA expression in peripheral blood mononuclear cells (PBMC) from patients with systemic lupus erythematosus (SLE)," Clinical and Experimental Immunology, vol. 122, no. 3, pp. 464-470, 2000.

[20] H. Mühl and J. Pfeilschifter, "Anti-inflammatory properties of pro-inflammatory interferon- $\gamma$," International Immunopharmacology, vol. 3, no. 9, pp. 1247-1255, 2003.

[21] S. Ehrt, D. Schnappinger, S. Bekiranov et al., "Reprogramming of the macrophage transcriptome in response to interferon- $\gamma$ and mycobacterium tuberculosis: signaling roles of nitric oxide synthase-2 and phagocyte oxidase," Journal of Experimental Medicine, vol. 194, no. 8, pp. 1123-1140, 2001.

[22] J. E. McLaren and D. P. Ramji, "Interferon gamma: a master regulator of atherosclerosis," Cytokine and Growth Factor Reviews, vol. 20, no. 2, pp. 125-135, 2009.

[23] P. Schneider, F. MacKay, V. Steiner et al., "BAFF, a novel ligand of the tumor necrosis factor family, stimulates B cell growth," Journal of Experimental Medicine, vol. 189, no. 11, pp. 1747-1756, 1999.

[24] P. A. Moore, O. Belvedere, A. Orr et al., "BLyS: member of the tumor necrosis factor family and B lymphocyte stimulator," Science, vol. 285, no. 5425, pp. 260-263, 1999.

[25] H.-B. Shu and H. Johnson, "B cell maturation protein is a receptor for the tumor necrosis factor family member TALL1," Proceedings of the National Academy of Sciences of the United States of America, vol. 97, no. 16, pp. 9156-9161, 2000.

[26] A. Mukhopadhyay, J. Ni, Y. Zhai, G.-L. Yu, and B. B. Aggarwal, "Identification and characterization of a novel cytokine, THANK, a TNF homologue that activates apoptosis, nuclear factor- $\kappa \mathrm{B}$, and c-jun NH2-terminal kinase," Journal of Biological Chemistry, vol. 274, no. 23, pp. 1597815981, 1999. 
[27] M. B. Litinskiy, B. Nardelli, D. M. Hilbert et al., "DCs induce CD40-independent immunoglobulin class switching through BLyS and APRIL," Nature Immunology, vol. 3, no. 9, pp. 822-829, 2002.

[28] B. Nardelli, O. Belvedere, V. Roschke et al., "Synthesis and release of B-lymphocyte stimulator from myeloid cells," Blood, vol. 97, no. 1, pp. 198-204, 2001.

[29] F. Lavie, C. Miceli-Richard, J. Quillard, S. Roux, P. Leclerc, and X. Mariette, "Expression of BAFF (BLyS) in T cells infiltrating labial salivary glands from patients with Sjogren's syndrome," Journal of Pathology, vol. 202, no. 4, pp. 496-502, 2008.

[30] P. Scapini, B. Nardelli, G. Nadali et al., "G-CSF-stimulated neutrophils are a prominent source of functional BLyS," Journal of Experimental Medicine, vol. 197, no. 3, pp. 297302, 2003.

[31] C. A. Ogden, J. D. Pound, B. K. Batth et al., "Enhanced apoptotic cell clearance capacity and B cell survival factor production by IL-10-activated macrophages: implications for Burkitt's lymphoma," Journal of Immunology, vol. 174, no. 5, pp. 3015-3023, 2005.

[32] P. Rieckmann, J. M. Tuscano, and J. H. Kehrl, "Tumor necrosis factor- $\alpha$ (TNF- $\alpha$ ) and interleukin-6 (IL-6) in Blymphocyte function," Methods, vol. 11, no. 1, pp. 128-132, 1997.

[33] W. Vanden Berghe, L. Vermeulen, G. De Wilde, K. De Bosscher, E. Boone, and G. Haegeman, "Signal transduction by tumor necrosis factor and gene regulation of the inflammatory cytokine interleukin-6," Biochemical Pharmacology, vol. 60, no. 8, pp. 1185-1195, 2000.

[34] A. N. Theofilopoulos, S. Koundouris, D. H. Kono, and B. R. Lawson, "The role of IFN- $\gamma$ in systemic erythematosus: a challenge tothe Th1/Th2 paradigm in autoimmunity," Arthritis Research, vol. 3, no. 3, pp. 136-141, 2001.

[35] A. K. Palucka, J. Banchereau, P. Blanco, and V. Pascual, "The interplay of dendritic cell subsets in systemic lupus erythematosus," Immunology and Cell Biology, vol. 80, no. 5, pp. 484-488, 2002.

[36] E. Svenungsson, G.-Z. Fei, K. Jensen-Urstad, U. de Faire, A. Hamsten, and J. Frostegård, "TNF- $\alpha$ : a link between hypertriglyceridaemia and inflammation in SLE patients with cardiovascular disease," Lupus, vol. 12, no. 6, pp. 454461, 2003.

[37] Y. H. Rho, C. P. Chung, A. Oeser et al., "Novel cardiovascular risk factors in premature coronary atherosclerosis associated with systemic lupus erythematosus," Journal of Rheumatology, vol. 35, no. 9, pp. 1789-1794, 2008.

[38] M. J. Roman, B.-A. Shanker, A. Davis et al., "Prevalence and correlates of accelerated atherosclerosis in systemic lupus erythematosus," The New England Journal of Medicine, vol. 349, no. 25, pp. 2399-2406, 2006.

[39] D. A. Horwitz and C. O. Jacob, "The cytokine network in the pathogenesis of systemic lupus erythematosus and possible therapeutic implications," Springer Seminars in Immunopathology, vol. 16, no. 2-3, pp. 181-200, 1994.

[40] P. M. Ridker, C. H. Hennekens, J. E. Buring, and N. Rifai, "C-reactive protein and other markers of inflammation in the prediction of cardiovascular disease in women," The New England Journal of Medicine, vol. 342, no. 12, pp. 836-843, 2000.

[41] P. E. Spronk, E. J. ter Borg, P. C. Limburg, and C. G. M. Kallenberg, "Plasma concentration of IL-6 in systemic lupus erythematosus; an indicator of disease activity?" Clinical and Experimental Immunology, vol. 90, no. 1, pp. 106-110, 1992.
[42] O. Shovman, B. Gilburd, and Y. Shoenfeld, "The role of inflammatory cytokines in the pathogenesis of systemic lupus erythematosus-related atherosclerosis: a novel target for treatment?" Journal of Rheumatology, vol. 33, no. 3, pp. 445-447, 2006.

[43] T. Korn, M. Oukka, V. Kuchroo, and E. Bettelli, "Th17 cells: effector T cells with inflammatory properties," Seminars in Immunology, vol. 19, no. 6, pp. 362-371, 2007.

[44] M. Laan, J. Lötvall, K. F. Chung, and A. Lindén, "IL-17induced cytokine release in human bronchial epithelial cells in vitro: role of mitogen-activated protein (MAP) kinases," British Journal of Pharmacology, vol. 133, no. 1, pp. 200-206, 2001.

[45] A. M. Woltman, S. De Haij, J. G. Boonstra, S. J. P. Gobin, M. R. Daha, and C. Van Kooten, "Interleukin-17 and CD40Ligand synergistically enhance cytokine and chemokine production by renal epithelial cells," Journal of the American Society of Nephrology, vol. 11, no. 11, pp. 2044-2055, 2000.

[46] J. Witowski, K. Pawlaczyk, A. Breborowicz et al., "IL-17 stimulates intraperitoneal neutrophil infiltration through the release of GRO $\alpha$ chemokine from mesothelial cells," Journal of Immunology, vol. 165, no. 10, pp. 5814-5821, 2000.

[47] M. J. Ruddy, F. Shen, J. B. Smith, A. Sharma, and S. L. Gaffen, "Interleukin-17 regulates expression of the CXC chemokine LIX/CXCL5 in osteoblasts: implications for inflammation and neutrophil recruitment," Journal of Leukocyte Biology, vol. 76, no. 1, pp. 135-144, 2004.

[48] S. Agarwal, R. Misra, and A. Aggarwal, "Interleukin 17 levels are increased in juvenile idiopathic arthritis synovial fluid and induce synovial fibroblasts to produce proinflammatory cytokines and matrix metalloproteinases," Journal of Rheumatology, vol. 35, no. 3, pp. 515-519, 2008.

[49] C. Albanesi, A. Cavani, and G. Girolomoni, "IL-17 is produced by nickel-specific $\mathrm{T}$ lymphocytes and regulates ICAM-1 expression and chemokine production in human keratinocytes: synergistic or antagonist effects with IFN- $\gamma$ and TNF- $\alpha$," Journal of Immunology, vol. 162, no. 1, pp. 494502, 1999.

[50] P. Schwarzenberger, W. Huang, Y. Peng et al., "Requirement of endogenous stem cell factor and granulocyte-colonystimulating factor for IL-17-mediated granulopoiesis," Journal of Immunology, vol. 164, no. 9, pp. 4783-4789, 2000.

[51] X.-Y. Cai, C. P. Gommoll Jr., L. Justice, S. K. Narula, and J. S. Fine, "Regulation of granulocyte colony-stimulating factor gene expression by interleukin-17," Immunology Letters, vol. 62, no. 1, pp. 51-58, 1998.

[52] M. Laan, Z.-H. Cui, H. Hoshino et al., "Neutrophil recruitment by human IL-17 via C-X-C chemokine release in the airways," Journal of Immunology, vol. 162, no. 4, pp. 23472352, 1999.

[53] J. Maertzdorf, A. D. M. E. Osterhaus, and G. M. G. M. Verjans, "IL-17 expression in human herpetic stromal keratitis: modulatory effects on chemokine production by corneal fibroblasts," Journal of Immunology, vol. 169, no. 10, pp. 5897-5903, 2002.

[54] R. L. Van Bezooijen, S. E. Papapoulos, and C. W. G. M. Löwik, "Effect of interleukin-17 on nitric oxide production and osteoclastic bone resorption: is there dependency on nuclear factor- $\kappa \mathrm{B}$ and receptor activator of nuclear factor $\kappa \mathrm{B}$ (RANK)/RANK ligand signaling?" Bone, vol. 28, no. 4, pp. 378-386, 2001.

[55] M. J. Ruddy, G. C. Wong, X. K. Liu et al., "Functional cooperation between interleukin-17 and tumor necrosis factor- $\alpha$ is mediated by CCAAT/enhancer-binding protein 
family members," Journal of Biological Chemistry, vol. 279, no. 4, pp. 2559-2567, 2004.

[56] T. Aarvak, M. Chabaud, P. Miossec, and J. B. Natvig, "IL-17 is produced by some proinflammatory Th1/Th0 cells but not by Th2 cells," Journal of Immunology, vol. 162, no. 3, pp. 12461251, 1999.

[57] C. Lock, G. Hermans, R. Pedotti et al., "Gene-microarray analysis of multiple sclerosis lesions yields new targets validated in autoimmune encephalomyelitis," Nature Medicine, vol. 8, no. 5, pp. 500-508, 2002.

[58] C. K. Wong, L. C. W. Lit, L. S. Tam, E. K. M. Li, P. T. Y. Wong, and C. W. K. Lam, "Hyperproduction of IL-23 and IL-17 in patients with systemic lupus erythematosus: implications for Th17-mediated inflammation in auto-immunity," Clinical Immunology, vol. 127, no. 3, pp. 385-393, 2008.

[59] J. C. Crispín, M. Oukka, G. Bayliss et al., "Expanded double negative $\mathrm{T}$ cells in patients with systemic lupus erythematosus produce IL-17 and infiltrate the kidneys," Journal of Immunology, vol. 181, no. 12, pp. 8761-8766, 2008.

[60] S. Shivakumar, G. C. Tsokos, and S. K. Datta, "T cell receptor $\alpha / \beta$ expressing double-negative (CD4-/CD8-) and $\mathrm{CD} 4+\mathrm{T}$ helper cells in humans augment the production of pathogenic anti-DNA autoantibodies associated with lupus nephritis," Journal of Immunology, vol. 143, no. 1, pp. 103112, 1989.

[61] R. E. Eid, D. A. Rao, J. Zhou et al., "Interleukin-17 and interferon- $\gamma$ are produced concomitantly by human coronary artery-infiltrating T cells and act synergistically on vascular smooth muscle cells," Circulation, vol. 119, no. 10, pp. 1424-1432, 2009.

[62] E. F. Morand, M. Leech, and J. Bernhagen, "MIF: a new cytokine link between rheumatoid arthritis and atherosclerosis," Nature Reviews Drug Discovery, vol. 5, no. 5, pp. 399 $411,2006$.

[63] A. Zernecke, J. Bernhagen, and C. Weber, "Macrophage migration inhibitory factor in cardiovascular disease," Circulation, vol. 117, no. 12, pp. 1594-1602, 2008.

[64] K. Shimizu, R. N. Mitchell, and P. Libby, "Inflammation and cellular immune responses in abdominal aortic aneurysms," Arteriosclerosis, Thrombosis, and Vascular Biology, vol. 26, no. 5, pp. 987-994, 2006.

[65] S. Saeland, V. Duvert, I. Moreau, and J. Banchereau, "Human B cell precursors proliferate and express CD23 after CD40 ligation," Journal of Experimental Medicine, vol. 178, no. 1, pp. 113-120, 1993.

[66] S. Lederman, M. J. Yellin, A. M. Cleary et al., "T-BAM/CD40L on helper T lymphocytes augments lymphokine-induced B cell Ig isotype switch recombination and rescues B cells from programmed cell death," Journal of Immunology, vol. 152, no. 5, pp. 2163-2171, 1994.

[67] F. Mach, U. Schönbeck, and P. Libby, "CD40 signaling in vascular cells: a key role in atherosclerosis?" Atherosclerosis, vol. 137, supplement 1, pp. S89-S95, 1998.

[68] F. Mach, U. Schönbeck, G. K. Sukhova et al., "Functional CD40 ligand is expressed on human vascular endothelial cells, smooth muscle cells, and macrophages: implications for CD40-CD40 ligand signaling in atherosclerosis," Proceedings of the National Academy of Sciences of the United States of America, vol. 94, no. 5, pp. 1931-1936, 1997.

[69] U. Schonbeck, F. Mach, G. K. Sukhova et al., "CD40 ligation induces tissue factor expression in human vascular smooth muscle cells," American Journal of Pathology, vol. 156, no. 1, pp. 7-14, 2000.
[70] A. B. Lee, T. Godfrey, K. G. Rowley et al., "Traditional risk factor assessment does not capture the extent of cardiovascular risk in systemic lupus erythematosus," Internal Medicine Journal, vol. 36, no. 4, pp. 237-243, 2006.

[71] R. K. Vakkalanka, C. Woo, K. A. Kirou, M. Koshy, D. Berger, and M. K. Crow, "Elevated levels and functional capacity of soluble CD40 ligand in systemic lupus erythematosus sera," Arthritis and Rheumatism, vol. 42, no. 5, pp. 871-881, 1999.

[72] J. Yazdany and J. Davis, "The role of CD40 ligand in systemic lupus erythematosus,” Lupus, vol. 13, no. 5, pp. 377-380, 2004.

[73] K. Maas, S. Chan, J. Parker et al., "Cutting edge: molecular portrait of human autoimmune disease," Journal of Immunology, vol. 169, no. 1, pp. 5-9, 2002.

[74] M. K. Crow, S. George, S. A. Paget et al., "Expression of an interferon-alpha gene program in SLE," Arthritis and Rheumatism, vol. 46, supplement 9, p. S281, 2002.

[75] G.-M. Han, S.-L. Chen, N. Shen, S. Ye, C.-D. Bao, and Y.-Y. $\mathrm{Gu}$, "Analysis of gene expression profiles in human systemic lupus erythematosus using oligonucleotide microarray," Genes and Immunity, vol. 4, no. 3, pp. 177-186, 2003.

[76] L. Bennett, A. K. Palucka, E. Arce et al., "Interferon and granulopoiesis signatures in systemic lupus erythematosus blood," Journal of Experimental Medicine, vol. 197, no. 6, pp. 711-723, 2003.

[77] V. Rus, S. P. Atamas, V. Shustova et al., "Expression of cytokine- and chemokine-related genes in peripheral blood mononuclear cells from lupus patients by cDNA array," Clinical Immunology, vol. 102, no. 3, pp. 283-290, 2002.

[78] E. C. Baechler, F. M. Batliwalla, G. Karypis et al., "Interferoninducible gene expression signature in peripheral blood cells of patients with severe lupus," Proceedings of the National Academy of Sciences of the United States of America, vol. 100, no. 5, pp. 2610-2615, 2003.

[79] T. Ishii, H. Onda, A. Tanigawa et al., "Isolation and expression profiling of genes upregulated in the peripheral blood cells of systemic lupus erythematosus patients," DNA Research, vol. 12, no. 6, pp. 429-439, 2005.

[80] M. K. Crow and J. Wohlgemuth, "Microarray analysis of gene expression in lupus," Arthritis Research and Therapy, vol. 5, no. 6, pp. 279-287, 2003.

[81] X. Qing and C. Putterman, "Gene expression profiling in the study of the pathogenesis of systemic lupus erythematosus," Autoimmunity Reviews, vol. 3, no. 7-8, pp. 505-509, 2004.

[82] K. A. Kirou, C. Lee, S. George et al., "Coordinate overexpression of interferon- $\alpha$-induced genes in systemic lupus erythematosus," Arthritis and Rheumatism, vol. 50, no. 12, pp. 3958-3967, 2004.

[83] S. L. Musone, K. E. Taylor, T. T. Lu et al., "Multiple polymorphisms in the TNFAIP3 region are independently associated with systemic lupus erythematosus," Nature Genetics, vol. 40, no. 9, pp. 1062-1064, 2008.

[84] K. L. Graham, L. Y. Lee, J. P. Higgins, L. Steinman, P. J. Utz, and P. P. Ho, "Failure of oral atorvastatin to modulate a murine model of systemic lupus erythematosus," Arthritis and Rheumatism, vol. 58, no. 7, pp. 2098-2104, 2008.

[85] E. F. Remmers, R. M. Plenge, A. T. Lee et al., "STAT4 and the risk of rheumatoid arthritis and systemic lupus erythematosus," The New England Journal of Medicine, vol. 357, no. 10, pp. 977-986, 2007.

[86] A. L. Sestak, S. K. Nath, A. H. Sawalha, and J. B. Harley, "Current status of lupus genetics," Arthritis Research and Therapy, vol. 9, no. 3, Article ID 210, 2007. 
[87] E. J. Pavón, P. Muñoz, A. Lario et al., "Proteomic analysis of plasma from patients with systemic lupus erythematosus: increased presence of haptoglobin alpha2 polypeptide chains over the alphal isoforms," Proteomics, vol. 6, supplement 1, pp. S282-S292, 2006.

[88] M. Melamed-Frank, O. Lache, B. I. Enav et al., "Structurefunction analysis of the antioxidant properties of haptoglobin," Blood, vol. 98, no. 13, pp. 3693-3698, 2001.

[89] M. R. Langlois and J. R. Delanghe, "Biological and clinical significance of haptoglobin polymorphism in humans," Clinical Chemistry, vol. 42, no. 10, pp. 1589-1600, 1996.

[90] A. P. Levy, J. E. Levy, S. Kalet-Litman et al., "Haptoglobin genotype is a determinant of iron, lipid peroxidation, and macrophage accumulation in the atherosclerotic plaque," Arteriosclerosis, Thrombosis, and Vascular Biology, vol. 27, no. 1, pp. 134-140, 2007.

[91] J. Guetta, M. Strauss, N. S. Levy, L. Fahoum, and A. P. Levy, "Haptoglobin genotype modulates the balance of Th1/Th2 cytokines produced by macrophages exposed to free hemoglobin," Atherosclerosis, vol. 191, no. 1, pp. 48-53, 2007.

[92] M. Shor, M. Boaz, D. Gavish, J. Wainshtein, Z. Matas, and M. Shargorodsky, "Relation of haptoglobin phenotype to early vascular changes in patients with diabetes mellitus," American Journal of Cardiology, vol. 100, no. 12, pp. 17671770, 2007.

[93] M. Petri, R. Roubenoff, G. E. Dallal, M. R. Nadeau, J. Selhub, and I. H. Rosenberg, "Plasma homocysteine as a risk factor for atherothrombotic events in systemic lupus erythematosus," The Lancet, vol. 348, no. 9035, pp. 1120 1124, 1996.

[94] S. L. Westlake, A. N. Colebatch, J. Baird et al., "The effect of methotrexate on cardiovascular disease in patients with rheumatoid arthritis: a systematic literature review," Rheumatology, vol. 49, no. 2, pp. 295-307, 2009.

[95] S. I. van Leuven, J. J. P. Kastelein, A. C. Allison, M. R. Hayden, and E. S. G. Stroes, "Mycophenolate mofetil (MMF): firing at the atherosclerotic plaque from different angles?" Cardiovascular Research, vol. 69, no. 2, pp. 341-347, 2006.

[96] F. Monneaux and S. Muller, "Molecular therapies for systemic lupus erythematosus: clinical trials and future prospects," Arthritis Research \& Therapy, vol. 11, no. 3, pp. 234-243, 2009.

[97] Y. Yao, L. Richman, B. W. Higgs et al., "Neutralization of interferon- $\alpha / \beta$-inducible genes and downstream effect in a phase I trial of an anti-interferon- $\alpha$ monoclonal antibody in systemic lupus erythematosus," Arthritis and Rheumatism, vol. 60, no. 6, pp. 1785-1796, 2009.

[98] D. Hürlimann, A. Forster, G. Noll et al., "Anti-tumor necrosis factor- $\alpha$ treatment improves endothelial function in patients with rheumatoid arthritis," Circulation, vol. 106, no. 17, pp. 2184-2187, 2002.

[99] C. Gonzalez-Juanatey, J. Llorca, C. Garcia-Porrua, J. Martin, and M. A. Gonzalez-Gay, "Effect of anti-tumor necrosis factor $\alpha$ therapy on the progression of subclinical atherosclerosis in severe rheumatoid arthritis," Arthritis Care and Research, vol. 55, no. 1, pp. 150-153, 2006.

[100] M. A. Gonzales-Gay, M. T. Garcia-Unzueta, J. M. De Matias et al., "Influence of anti-TNF- $\alpha$ infliximab therapy on adhesion molecules associated with atherogenesis in patients with rheumatoid arthritis," Clinical and Experimental Rheumatology, vol. 24, no. 4, pp. 373-379, 2006.

[101] D. N. Kiortsis, A. K. Mavridis, S. Vasakos, S. N. Nikas, and A. A. Drosos, "Effects of infliximab treatment on insulin resistance in patients with rheumatoid arthritis and ankylosing spondylitis," Annals of the Rheumatic Diseases, vol. 64, no. 5, pp. 765-766, 2005.

[102] C. Popa, F. H. J. van den Hoogen, T. R. D. J. Radstake et al., "Modulation of lipoprotein plasma concentrations during long-term anti-TNF therapy in patients with active rheumatoid arthritis," Annals of the Rheumatic Diseases, vol. 66, no. 11, pp. 1503-1507, 2007.

[103] G. E. McKellar, D. W. McCarey, N. Sattar, and I. B. McInnes, "Role for TNF in atherosclerosis? Lessons from autoimmune disease," Nature Reviews in Cardiology, vol. 6, no. 6, pp. 410417, 2009.

[104] M. Y. Karim, C. N. Pisoni, and M. A. Khamashta, "Update on immunotherapy for systemic lupus erythematosus-what's hot and what's not!," Rheumatology, vol. 48, no. 4, pp. 332341, 2009.

[105] M. Aringer, W. B. Graninger, G. Steiner, and J. S. Smolen, "Safety and efficacy of tumor necrosis factor $\alpha$ blockade in systemic lupus erythematosus: an open-label study," Arthritis and Rheumatism, vol. 50, no. 10, pp. 3161-3169, 2004.

[106] M. Aringer, G. Steiner, W. B. Graninger, E. Höfler, C. W. Steiner, and J. S. Smolen, "Effects of short-term infliximab therapy on autoantibodies in systemic lupus erythematosus," Arthritis and Rheumatism, vol. 56, no. 1, pp. 274-279, 2007.

[107] M. Ramos-Casals, P. Brito-Zerón, M.-J. Soto, M.-J. Cuadrado, and M. A. Khamashta, "Autoimmune diseases induced by TNF-targeted therapies," Best Practice and Research: Clinical Rheumatology, vol. 22, no. 5, pp. 847-861, 2008.

[108] L. Llorente, Y. Richaud-Patin, C. Garcia-Padilla et al., "Clinical and biologic effects of anti-interleukin-10 monoclonal antibody administration in systemic lupus erythematosus," Arthritis and Rheumatism, vol. 43, no. 8, pp. 1790-1800, 2000.

[109] H. Le Buanec, L. Delavallée, N. Bessis et al., "TNF $\alpha$ kinoid vaccination-induced neutralizing antibodies to TNF $\alpha$ protect mice from autologous $\mathrm{TNF} \alpha$-driven chronic and acute inflammation," Proceedings of the National Academy of Sciences of the United States of America, vol. 103, no. 51, pp. 19442-19447, 2006.

[110] R. P. Taylor and M. A. Lindorfer, "Drug Insight: the mechanism of action of rituximab in autoimmune diseasethe immune complex decoy hypothesis," Nature Clinical Practice Rheumatology, vol. 3, no. 2, pp. 86-95, 2007.

[111] T. Cerny, B. Borisch, M. Introna, P. Johnson, and A. L. Rose, "Mechanism of action of rituximab," Anti-Cancer Drugs, vol. 13, supplement 2, pp. S3-S10, 2002.

[112] D. G. Maloney, B. Smith, and A. Rose, "Rituximab: mechanism of action and resistance," Seminars in Oncology, vol. 29, no. 1, supplement 2, pp. 2-9, 2002.

[113] M. J. Leandro, G. Cambridge, J. C. Edwards, M. R. Ehrenstein, and D. A. Isenberg, "B-cell depletion in the treatment of patients with systemic lupus erythematosus: a longitudinal analysis of 24 patients," Rheumatology, vol. 44, no. 12, pp. 1542-1545, 2005.

[114] R. J. Looney, J. H. Anolik, D. Campbell et al., "B cell depletion as a novel treatment for systemic lupus erythematosus: a phase I/II dose-escalation trial of rituximab," Arthritis and Rheumatism, vol. 50, no. 8, pp. 2580-2589, 2004.

[115] M. Vigna-Perez, B. Hernández-Castro, O. ParedesSaharopulos et al., "Clinical and immunological effects of Rituximab in patients with lupus nephritis refractory to conventional therapy: a pilot study," Arthritis Research and Therapy, vol. 8, no. 3, Article ID R83, 2006. 
[116] P. P. Sfikakis, J. N. Boletis, S. Lionaki et al., "Remission of proliferative lupus nephritis following B cell depletion therapy is preceded by down-regulation of the $\mathrm{T}$ cell costimulatory molecule CD40 ligand: an open-label trial," Arthritis and Rheumatism, vol. 52, no. 2, pp. 501-513, 2005.

[117] I. Gunnarsson, B. Sundelin, T. Jónsdóttir, S. H. Jacobson, E. W. Henriksson, and R. F. van Vollenhoven, "Histopathologic and clinical outcome of rituximab treatment in patients with cyclophosphamide-resistant proliferative lupus nephritis," Arthritis and Rheumatism, vol. 56, no. 4, pp. 1263-1272, 2007.

[118] M. Tokunaga, K. Saito, D. Kawabata et al., "Efficacy of rituximab (anti-CD20) for refractory systemic lupus erythematosus involving the central nervous system," Annals of the Rheumatic Diseases, vol. 66, no. 4, pp. 470-475, 2007.

[119] T. Jónsdóttir, I. Gunnarsson, A. Risselada, E. W. Henriksson, L. Klareskog, and R. F. van Vollenhoven, "Treatment of refractory SLE with rituximab plus cyclophosphamide: clinical effects, serological changes, and predictors of response," Annals of the Rheumatic Diseases, vol. 67, no. 3, pp. 330-334, 2008.

[120] J. M. Pego-Reigosa, T. Y. Lu, M. F. Fontanillo, V. D. Campo-Pérez, A. Rahman, and D. A. Isenberg, "Long-term improvement of lipid profile in patients with refractory systemic lupus erythematosus treated with B-cell depletion therapy: a retrospective observational study," Rheumatology, vol. 49, no. 4, pp. 691-696, 2010.

[121] D. M. Klinman, D. Tross, S. Klaschik, H. Shirota, and T. Sato, "Therapeutic applications and mechanisms underlying the activity of immunosuppressive oligonucleotides," Annals of the New York Academy of Sciences, vol. 1175, pp. 80-88, 2009.

[122] G. Zandman-Goddard, M. Blank, and Y. Shoenfeld, "Intravenous immunoglobulins in systemic lupus erythematosus: from the bench to the bedside," Lupus, vol. 18, no. 10, pp. 884-888, 2009.

[123] Y. Levy, Y. Sherer, A. Ahmed et al., "A study of 20 SLE patients with intravenous immunoglobulin-clinical and serologic response," Lupus, vol. 8, no. 9, pp. 705-712, 1999.

[124] Ch. Lopez-Pedrera, M. A. Aguirre, P. Ruiz et al., "Global effects of the HMG-CoA Reductase inhibitor Fluvastatin on the procoagulant and proinflammatory features of monocytes from APS patients," Annals of Rheumatic Diseases, vol. 68, supplement 3, p. 245, 2009.

[125] G. A. Ferreira, T. P. Navarro, R. W. Telles, L. E. C. Andrade, and E. I. Sato, "Atorvastatin therapy improves endothelialdependent vasodilation in patients with systemic lupus erythematosus: an 8 weeks controlled trial," Rheumatology, vol. 46, no. 10, pp. 1560-1565, 2007.

[126] P. J. Kotyla, B. Sliwinska-Kotyla, and E. J. Kucharz, "TNF$\alpha$ as a potential target in the treatment of systemic lupus erythematosus: a role for the HMG-CoA reductase inhibitor simvastatin," Journal of Rheumatology, vol. 33, no. 11, pp. 2361-2363, 2006.

[127] G. E. Norby, I. Holme, B. Fellström et al., "Effect of fluvastatin on cardiac outcomes in kidney transplant patients with systemic lupus erythematosus a randomized placebocontrolled study," Arthritis and Rheumatism, vol. 60, no. 4, pp. 1060-1064, 2009. 


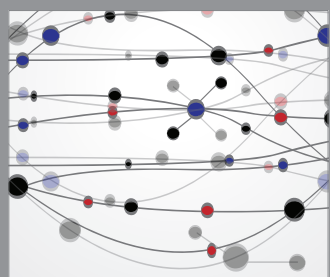

The Scientific World Journal
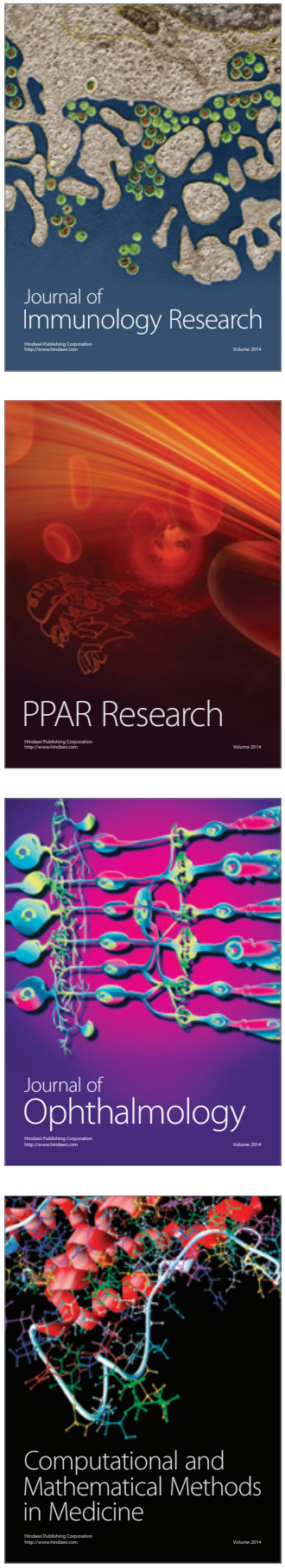

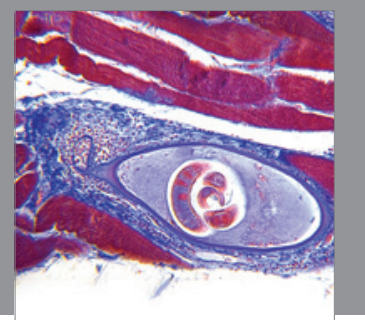

Gastroenterology

Research and Practice
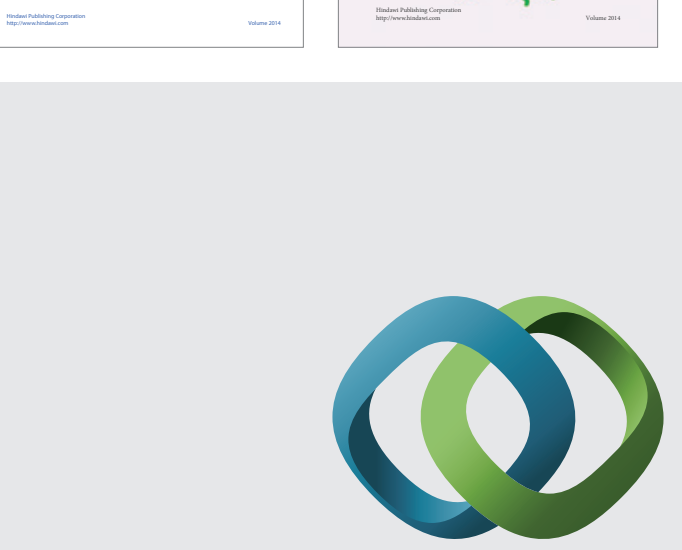

\section{Hindawi}

Submit your manuscripts at

http://www.hindawi.com
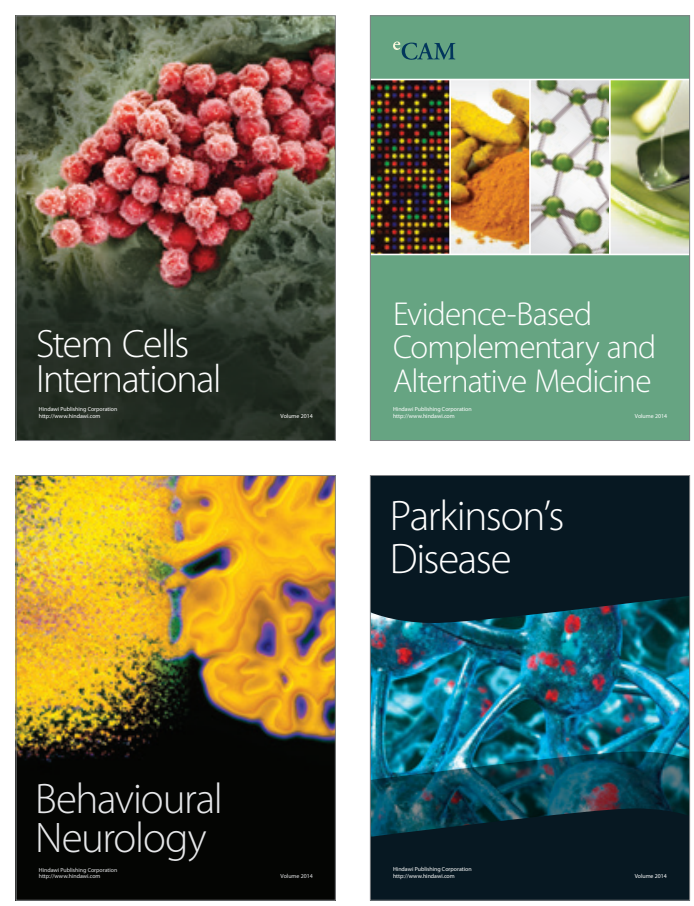

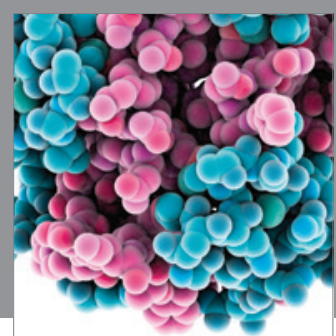

Journal of
Diabetes Research

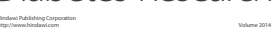

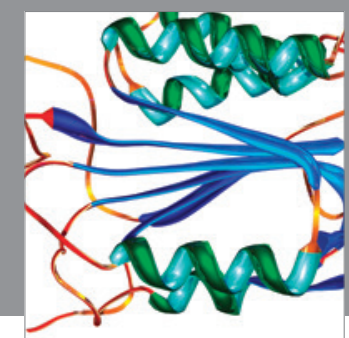

Disease Markers
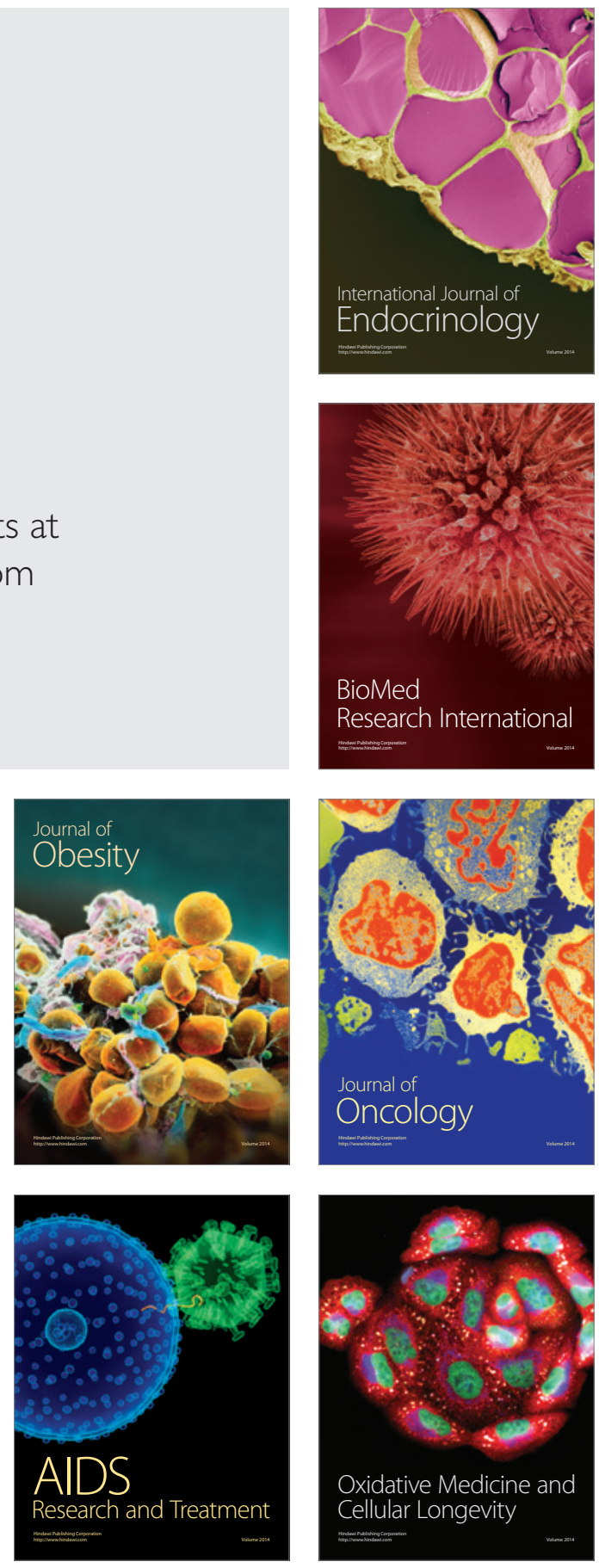